Sten DE GEER

\title{
Das geologische Fennoskandia und das geographische Baltoskandia
}

Stockholm : [s.n.]

1928 


\section{Trükise digitaalkoopia ehk e-raamatu tellimine (eBooks on Demand (EOD)) -miljonid raamatud vaid hiireklõpsu kaugusel rohkem kui kümnes Eu- roopa riigis!}

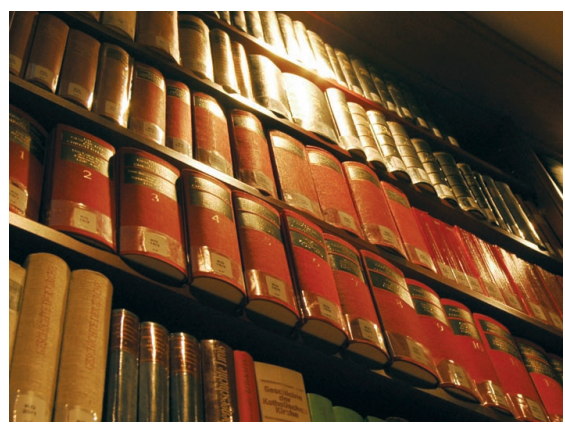

Täname Teid, et valisite EOD!

Euroopa raamatukogudes säilitatakse miljoneid 15.20. sajandi raamatuid. Kõik need raamatud on nüüd kättesaadavad e-raamatuna — vaid hiireklõpsu kaugusel 24 tundi ööpäevas, 7 päeva nädalas. Tehke otsing mõne EOD võrgustikuga liitunud raamatukogu elektronkataloogis ja tellige raamatust digitaalkoopia ehk e-raamat kogu maailmast. Soovitud raamat digiteeritakse ja tehakse Teile kättesaadavaks digitaalkoopiana ehk e-raamatuna.

\section{Miks e-raamat?}

- Saate kasutada standardtarkvara digitaalkoopia lugemiseks arvutiekraanil, suurendada pilti või navigeerida läbi terve raamatu.

- Saate välja trükkida üksikuid lehekülgi või kogu raamatu.

- Saate kasutada üksikterminite täistekstotsingut nii ühe faili kui failikomplekti (isikliku e-raamatukogu) piires.

- Saate kopeerida pilte ja tekstiosi teistesse rakendustesse, näiteks tekstitöötlusprogrammidesse.

\section{Tingimused}

EOD teenust kasutades nõustute Te tingimustega, mille on kehtestanud raamatut omav raamatukogu. EOD võimaldab juurdepääsu digiteeritud dokumentidele rangelt isiklikel, mittekommertseesmärkidel. Kui soovite digitaalkoopiat muuks otstarbeks, palun võtke ühendust raamatukoguga.

- Tingimused inglise keeles: http://books2ebooks.eu/odm/html/utl/en/agb.html

○ Tingimused saksa keeles: http://books2ebooks.eu/odm/html/utl/et/agb.html

\section{Rohkem e-raamatuid}

Seda teenust pakub juba tosin raamatukogu enam kui kümnes Euroopa riigis. Lisainfo aadressil: http://books2ebooks.eu 


\section{STEN DE GEER.}

\section{DAS GEOLOGISCHE FENNOSKANDIA UND DAS GEOGRAPHISCHE BALTOSKANDIA.}

GEOGRAFISKA ANNALER 1928, H 1 o 2

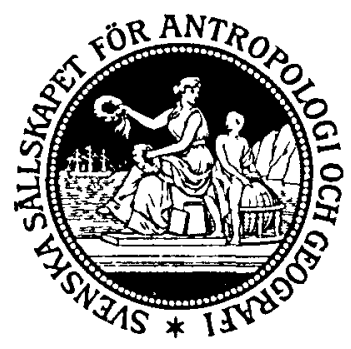




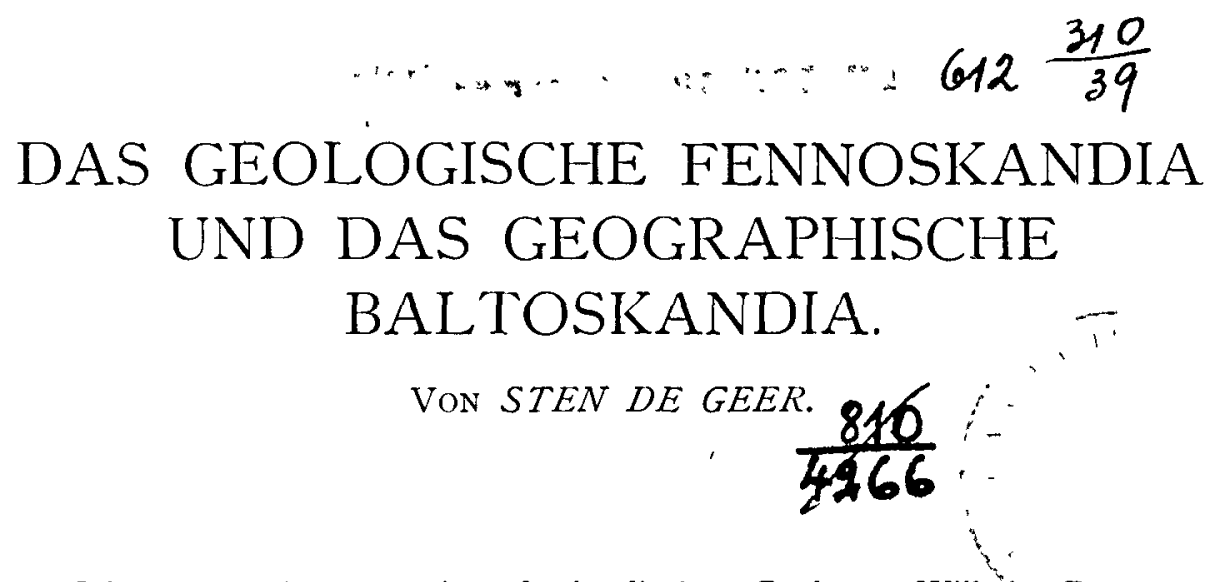

T $\mathrm{m}$ Jahre $\mathrm{r} 900$ ist von dem finnlandischen Geologen Wilhelm Ramsay vorgeschlagen worden das geologisch und landschaftlich auffallend einheitliche Urgebirgsgebiet von Nordeuropa mit dem einheitlichen Namen Fennoskandia zu bezeichnen. ${ }^{\mathrm{I}}$ Dieser Name hat sich seitdem in der wissenschaftlichen Litteratur eingeburgert. Das entsprechende Gebiet ist durch Karten gut bekannt geworden. Es umfasst etwa die staatlichen Gebiete von Schweden, Norwegen, Finnland, die Autonome Karelische Sovjetrepublik und das Verwaltungsgebiet Murmansk, gewöhnlich die Kolahalbinsel genannt. Der Begriff Fennoskandia wird unten etwas nàher definiert werden.

Fennoskandia ist ein rein naturlandschaftlicher Begriff. Die Verbreitungsgebiete des nordischen Volkes, der nordischen Kultur, der nordischen Geschichte und der nordischen Staaten decken sich nicht vollstandig mit Fennoskandia, ja weichen davon erheblich ab. Dasselbe gilt von einigen anderen Naturfaktoren mit geschlossenem Verbreitungsgebiet innerhalb Nordeuropas.

Die Abweichungen sind jedoch derart, dass sie nicht besonders auffallen. Sie werden sogar von Geographen oft ubergangen. Die Grenzen dieser anderen Verbreitungserscheinungen sind in der Hauptsache mit denen von Fennoskandia konform. Sie schliessen einen Grenzgurtel ein und runden das Gebiet von Nordeuropa ab.

Eine Abgrenzung der geographischen Region von Nordeuropa darf nicht einseitig sein. Die Grenze der Region geht eher dort, wo mehrere wichtige Verbreitungserscheinungen ubereinstimmende Grenzen zeigen, als dort, wo nur etwa eine Grenze liegt.

Es ist eine Aufgabe der Geographen, in diesem wie in ànlichen Fällen nach regional wichtigen Verbreitungserscheinungen mit geeigneter Verbreitung zu forschen.

Die Wichtigkeit ist schwierig zu bemessen oder zu vergleichen. Von der Verbreitung muss gefordert werden, dass sie in der Hauptsache das ganze Gebiet decke und nach allen Seiten eine Grenze aufweise.

Die Grenze des einzelnen Verbreitungsfaktors ware am besten eine absolute Grenze, so dass der Verbreitungsgegenstand ausserhalb der Grenze ganz fehlte.

I IV. Ramsay, Uber die geologische Entwıcklung der Halbinsel Kola, Fennia I6, I, 1900.

\section{TARTU ÖLIKOOLI RAAMATUKOGU}




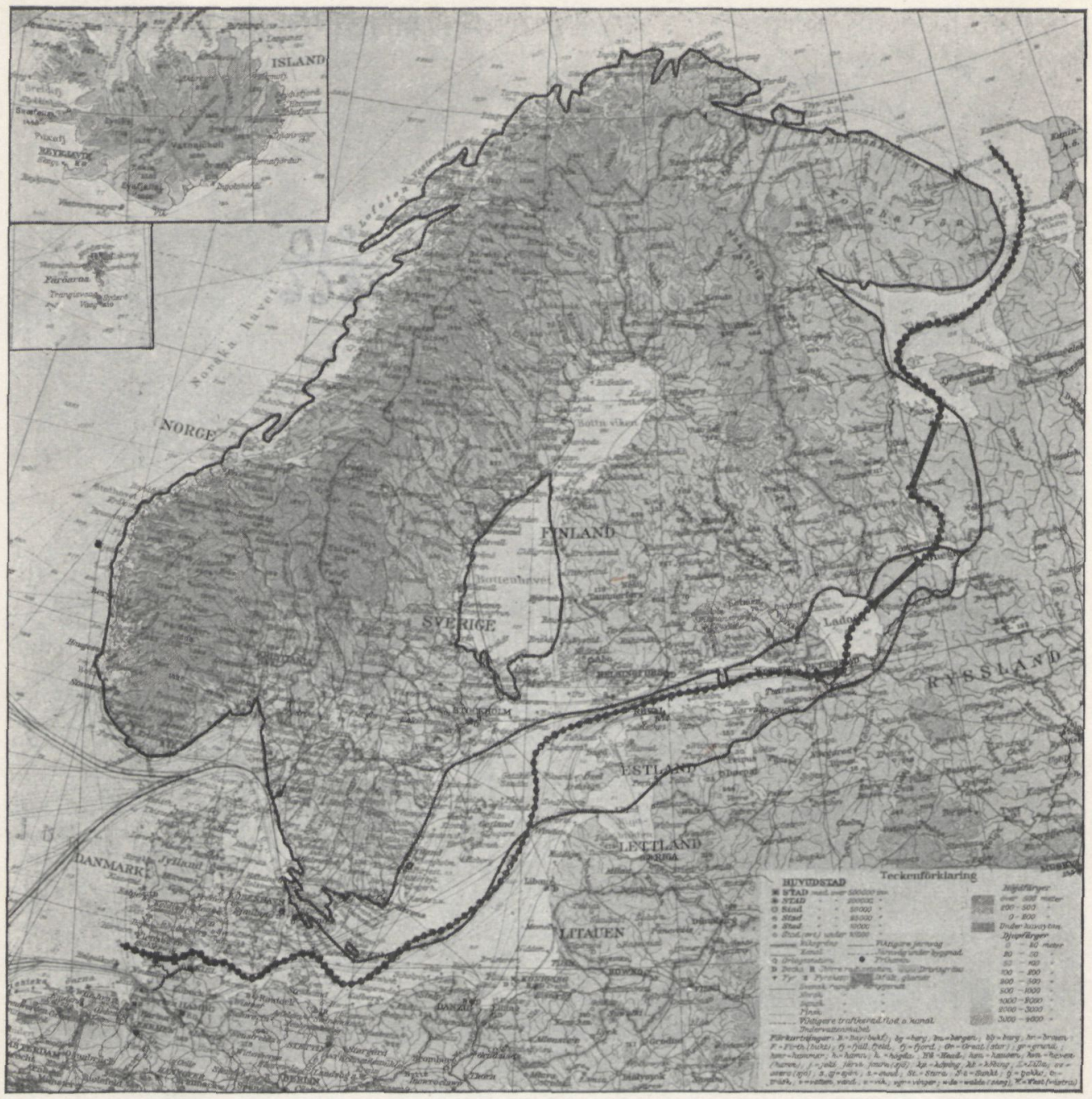

Karte I. Das Urgebirgsland Fennoskandia (innere, ausgezogene Linie) mit Übergangszone (äussere, ausgezogene Linie). Die Halbinselländer Nordeuropas (grobe und gepunktete Linie). ${ }^{\mathrm{T}}$ Massstab I : 16000000 .

Für wichtige Verbreitungsobjekte wäre es jedoch zulässig, eine relative Intensitätsgrenze auszuwählen. Ausserhalb einer solchen Grenze ist die Intensität oder die Dichte des Objekts geringer, innerhalb derselben grösser als die des gewählten Grenzmasses.

Die Wahl einer relativen Grenze erfordert eine besonders gute Konformität der Verbreitungsfläche im Verhältnis zu den anderen Verbreitungsflächen.

I Die Karten $1-6$ sind auf der Unterlage von Blatt 6 , Karte 7 auf der Unterlage von Blatt 4 in Nordisk Världsatlas, Stockholm I926, ausgeführt worden. 
Bei dem Suchen nach Verbreitungsfaktoren, die für die Abgrenzung des europäischen Nordens geeignet sind, hat es sich gezeigt, dass keine klimatischen und keine regional wichtigen biogeographischen Faktoren in Frage kommen können. Eine grosse Gruppe dieser Faktoren hat Verbreitungsgebiete, die nach dem Ozean im Westen oder nach dem Kontinent im Osten fortgehen, wie nach Norden oder nach Süden. Eine andere grosse Gruppe ist auf die skandinavische Fjäll-(Hochplateau-)region beschränkt oder auf andere begrenzte Teile der Region Nordeuropa und kann dẹshalb nicht in Betracht kommen.

Gefunden wurden nebst der Grenze des Fennoskandischen Urgebirgsgebietes drei Faktoren mit absoluten Naturgrenzen, von denen jedoch eine an der Grenze die Intensität Null hat. Dazu kommen fünf Faktoren mit Kulturgrenzen, von denen zwei nicht nach Südwesten hin ganz geschlossen sind und einer nur relativer Natur ist.

Die neun Faktoren sind die folgenden: 1) das Urgebirgsland Fennoskandia, 2) die Halbinselländer Nordeuropas, 3) Fennoskandia mit seiner durch Moränentopographie gekennzeichneten Randzone; 4) das fennoskandische Landhebungsgebiet, 5) das Kerngebiet der nordischen Rasse, 6) die beiden fennoskandischen Sprachgebiete, 7) das Verbreitungsgebiet des protestantischen Christentums, 8) die heutigen nordischen Staatsgebiete, und 9) die Maximalverbreitung der zwei tausendjährigen nordischen Staaten während der neueren Zeit.

I. Das Urgebirgsland Fennoskandia (Karte I, innere ausgezogene Linie). Eine Monographie der geologischen Region Fennoskandia gab in deutscher Sprache A. G.

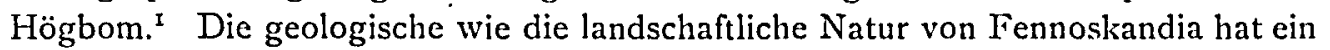
Gegenstück in Laurentia, das noch grössere Urgebirgsland von Nordamerika. Beide sind geschlossene, oval gerundete Gebiete mit je einer zentralen Depression, hier der Bottnische Busen, dort die Hudson Bay. Beide haben erhobene, kreuzweise zerbrochene und durch vormaliges Landeis in Fjordlandschaften herausmodellierte Plateauränder den ozeanischen Senkungsfeldern entlang, in Norwegen und in Labrador.

Die vielen Versuche, in der Fjordlandschaft wie in'der übrigen Urgebirgsfläche Spuren fluvialer Formserien zu finden, haben nicht zu sicheren Resultaten geführt.

Es gibt alle Übergangsformen des Reliefs von steilsten, $2000 \mathrm{~m}$ hohen Fjordformen bis zu ganz flachen Urgebirgsebenen unter und rings um die Reste mittelschwedischer Silurlagerplatten.

Ohne Rücksicht auf den Formenmassstab des Reliefs wird der Charakter der fennoskandischen Landfläche durch kreuzende Spaltensysteme der harten Gesteine bestimmt. Je nach der Intensität der Spaltensysteme und der Zeitdauer von der Entblössung der Urgebirgsfläche von der schützenden Silurdecke bis zum Abschmelzen des Inlandeises, hat dieses die gebrochene Fläche mehr oder weniger tief zu cinem charakteristischen Eckplateauland herausgeätzt.

I A. G. Högbom, Fennoskandia, Handbuch der Regionalen Geologie, IV Band, $3 \mathrm{Abt}$., Heidelberg 1913 . 
Die Wirkung des Eises war nur in untergeordnetem Grade von abschleifender, vielmehr hauptsächlich von losbrechender Natur, wie es die neuere schwedische Forschung durch exaktes Studium der Detailformen festgestellt hat. ${ }^{I}$ Die losbrechende Wirkung des Eises hat überall Ansätze zur Bildung von Talnetzen geschaffen, nicht von verzweigten Tälern wie in fluviatilen Landschaften. ${ }^{2}$

Die wenig geätzten Flächen sowie die Talnetzte sind, auch bei begrenzten Mengen von feinen Sedimenten, leicht ganz überdeckt worden, grössere anbaufăhige Areale bildend. Nur wenig oder schwierig kultiviert sind die zwischenliegenden eckigen Plateaufl̈chen, die mit steiniger Urgebirgsmoräne bedeckt und mit Nadelwald bewachsen sind, wenn sie nicht gar später unterhalb der marinen Grenze vom Meere ganz blossgelegt worden sind.

Die Talnetze und Eckplateaus mit Spaltenflächen und Rundhöckern als Kleinformen sind landschaftlich für ganz Fennoskandia von grundlegender Bedeutung und zunächst für Bewaldung und Anbau von bestimmendem Einfluss. Am Meere bildet eine solche Landschaft eine ausgeprägte Schärenküste.

Das einst vereiste Urgebirgsland ist somit ein vollwertiger regionbildender Faktor, dessen Grenze ganz geschlossen und dazu absolut ist. Die angeführten Verschiedenheiten in der Intensität dieses Landschaftstypus hat man bisher nicht als solche beachtet.

Karte I zeigt die Verbreitung des Gebietes von Fennoskandia nach der klas. sischen Karte von J. J. Sederholm. ${ }^{3}$ Die Grenzlinie auf den Meeresflächen ist nach bekannten oder wahrsclseinlichen Verwerfungslinien und nach den Kleinformen des Meeresbodens vom Verfasser gezogen worden, so dass dic Forderung einer allseitigen Umrahmung des Verbreitungsgebietes erfüllt worden ist.

Die Senkungsfelder des Skagerraks, des südlichen Bottnischen Busens und des Weissen Meeres, alle mit Boden von sedimentären Lagergesteinen, treten besonders deutlich auf der Karte hervor. Desgleichen die dreieckigen Busen Varangerfjord und Vestfjord, die Buchten beiderseits von Schonen, und die kleinen randlichen Horste von Hogland im Finnischen Busen, Skägganäs im Kalmarsund, Bornholm, sowie die Horste in Schonen.

Das Urgebirgsland von Fennoskandia hat eine engere Begrenzung als alle die anderen Faktoren. Es mag darum von einigem Interesse sein, die silurische Über. gangszone von Südosten her nach diesem Gebiet zu betrachten. Sie reicht vom Ladogasee bis Schonen, oder mit einigen anschliessenden kleineren Formationsgebieten vom Onegasee bis zum Kattegatt.

Absätze im Kalksteine (Glintlinien. Glint, schwed. Klint) und andere Kennzeichen

I Untersuchungen in schwedischer Sprache von K. E. Sahlström I9I4, G. Lundqvist I920, II. Nelson 1923; in deutscher Sprache von B. Asklund 1923, I. Högbom I925, E. Ljungner I927.

2 Verf., Geografiska Annaler 1926, S. I25 (Resümee in englischer Sprache).

3 Atlas öfver Finland 1910, Karte 5. Vgl. die neue Karte von Fennoskandia von B. Asklund, Nordisk Familjebok, 3. Auf., Bd. 7, S. 231, Stockholm I927. 
der gotlandischen Silurlandschaft haben allerdings nur Gotland und Öland, Dago und Ösel, Estland und das nördliche Ingermanland.

Obgleıch einige Silurgebiete auf der Skandinavischen Halbinsel mit zur Fennoskandischen Region gerechnet werden mussen, eine Art Musterung im einformigen Urgebirgsland hervorrufend, so kann diese silurische Ubergangszone doch kaum dorthin gerechnet werden. Sie bildet eher eine selbstandige Region dem Rande Fennoskandias entlang (Karte I, aussere ausgezogene Linie).

2. Die Halbinselländer Nordeuropas (Karte I, grobe und gepunktete_Linie). Im Suden von Eurasien zieht sich die eine Hauptregion von Gebirgsketten und Senkungsfeldern hin, die letzteren grösstenteils Meeresteile bildend, die Afrika und Australien abscheiden. Im Nordwesten von Eurasien ist die Kuste ebenfalls von kompliziertem Bau, indem ihr Inseln und Halbinseln vorgelagert sind.

Es liegen dort zwei Gruppen von etwas erhohten Landflachen, die Britischen Inseln und die Skandinavischen Halbinseln, jede gegenuber einer ozeanischen Senke, der Nordatlantischen und der Skandischen. Auf der Flachseeflache zwischen beiden liegt mehr entfernt die Insel Island.

Die Ähnlichkeit der Lage und Genesis der Britischen und Skandınavischen Inseln und Halbinseln wird besonders durch die erhöten, fjordgeteilten Nordwestrander beider Gebiete augenfallig.

In beiden Fallen hat die Isolierung von dem Kontinent mancherlei wichtige Folgeerscheinungen hervorgerufen, besonders auf dem kulturellen und historischen Gebiet.

Die Abgrenzungslinie der Skandinavischen Halbinselregion lauft durch das Weisse Meer, dann uber die Onega-Landenge $140 \mathrm{~km}$ zwischen Njuchtja und Povenets, dann durch den Onegasee, uber die Aunus (Olonets)- Landenge $130 \mathrm{~km}$ von Peda. seljga (im Suden von Petrozavodsk) nach Andrusovsk (1m Nordwesten von der Stadt Aunus), dann durch den Ladogasee und uber die Karelische Landenge $45 \mathrm{~km}$ von Schlusselburg nach dem Westrande von Leningrad. Die Scheidelinie lauft weiter sudwestlich durch die Mitte der Ostsee und scheidet die Halbinsel Jutland an der schmalsten Stelle vom Kontinent. Sie geht somit $35 \mathrm{~km}$ uber Land zwischen Schleswig und Husum.

Vier Landengen mit einer Gesamtbreite von $350 \mathrm{~km}$ verbinden das Halbinselsystem mit dem Kontinent.

Statt die schmalsten Stellen geradlinig zu uberqueren, konnte man die Scheidelinie làngs Flussen und Senken verlegen, wie entlang Uikujoki (Vygfluss), Svir, Neva und Eider oder dem Nord-Ostseekanal, ohne sehr wesentliche Ánderungen in dem Umfang der Halbinselregion zu veranlassen. Der Begriff der Halbinsel scheint jedoch die gerade Grenzlinie zu erfordern.

Es ist von Interesse zu sehen, dass die Scheidelinie der Hauptsaclie nach inner- 
halb der silurischen Grenzzone von Fennoskandia verläuft, Dänemark dazu einschliessend. Das Halbinselland reicht etwas weiter als das Urgebirgsland.

Die Konformität seiner Ausbreitung ist jedoch auffallend und scheint einen ursächlichen Zusammenhang anzudeuten. Es ist noch nicht bekannt, inwieweit die ungleichmässigen Landhebungen, Flexuren und Verwerfungen nebst selektiver Eiserosion zu den scheidenden Senken ausserhalb Fennoskandia beigetragen haben.

Die Halbinseln von Jütland und von Finnland-Karelen haben unmittelbare Verbindungen mit dem Kontinent, während die Skandinavische Halbinsel nur eine mittelbare Verbindung hat. Sie kann nicht gut von der.Finnischen Halbinsel getrennt werden.

Als ein riesiges Übergangsgebiet sei genannt das nördliche Fennoskandia zwischen der Linie Bottnischer Busen-Kantalaks und der Linie Bottnischer Busen-Vestfjorden, je etwa $360 \mathrm{~km}$ lang. Die spärliche Besiedlung dieses Gebiets macht es jedoch in vielen Hinsichten zu einem wichtigen Scheidegebiet.

Somit hat die eigentliche Skandinavische Halbinsel eine mehr ausgesprochene Halbinselnatur als die übrigen nordischen Halbinseln, was von Bedeutung hinsichtlich Rasse, Staatenentwicklung und Geschichte gewesen ist.

3. Fennoskandia mit seiner durch Moränentopographie gekennzeichneten Randzone (Karte 2, gepunktete Linie). ${ }^{\mathrm{I}} \quad$ Zwar herrschen die nackten Felsfächen in den Fjord- und Schärenlandschaften, aber der weitaus grösste Teil von Fennoskandia ist von steiniger Urgebirgsmoräne bedeckt. Ausserhalb Fennoskandia hat das Landeis weiche Sedimentgesteine erodiert und einen lehmartigen Moränenstoff noch weiter aussen in mächtigen Massen abgelagert.

Das Land der Steinmoräne innerhalb Fennoskandia ist hauptsächlich mit Nadelwald bewachsen, während das Land der Lehmmoräne ausserhalb Fennoskandia meist augebaut ist.

Auch die Zone der Lehmmoräne besteht aus zwei Gürteln von landschaftlich wesentlich verschiedenem Charakter. Nur der Gürtel des inneren und jüngeren Moränenlandes bewahrt die landschaftlichen Sonderzüge eines Lehmmoränenlandes, wie die sanftwellige Landfäche und den Reichtum an unregelmässig geformten grösseren nebst zahlreichen kleinen Seen. Die meistens flach geneigten, angebauten Lehmfächen sind oft mit Baumgruppen geschmückt oder wechseln mit kleinen Laubwäldern ab. Es sind vorwiegend Buchenhaine im milden Südwesten von Dänemark bis Pommern, aber Eichenhaine von dort ins winterkalte Russland, hinein.

Es ist die Grenze dieses jüngeren Lehmmoränenlandes, die auf Karte 2 erscheint. Die Mächtigheit der Moränendecke wechselt. Sie ist dünn auf den silurischen Kalksteinplatten von Gotland und Estland, mässig anderwärts, und scheint im allgemeinen am mächtigsten dort zu sein, wo die wellige Seenlandschaft vorherrscht.

I Die Moränenzone wurde westlich von der Weichsel nach G. De Geer, Geol, Rundschau 1927, S. 417 abgegrentz, östlich davon nach W. Ramsay, Geologins grunder, Helsingfors 1909, S. 433. 


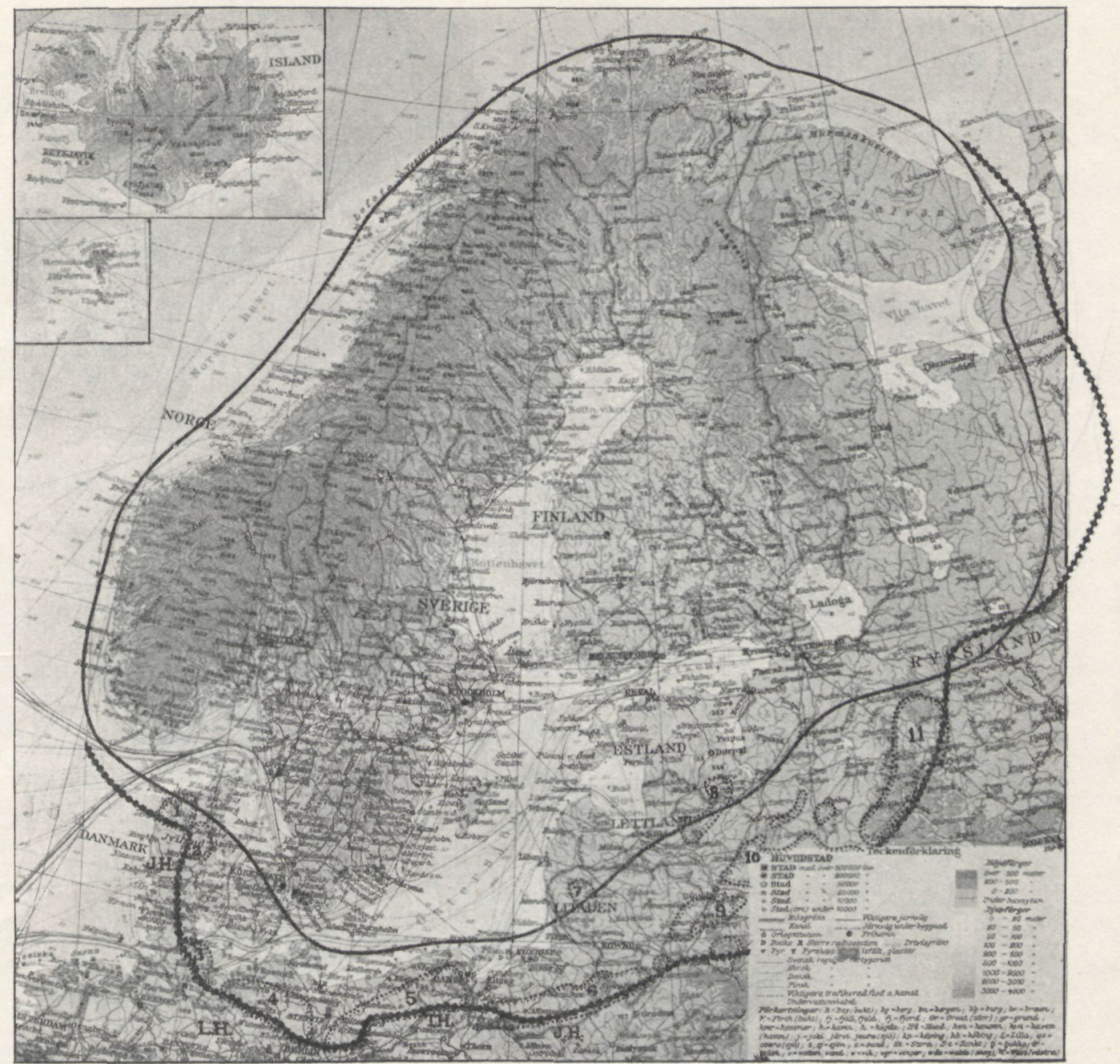

Karte 2. Fennoskandia mit seiner durch Moränentopographie (2-II) gekennzeichneten Randzone (gepunktete Linie). Das Fennoskandische Landhebungsgebiet (innere ausgezogene Linie). Massstab i : 16000000 .

Solche Gebiete haben in Deutschland die nützliche, aber nicht ganz zutreffende geographische Bezeichnung Seenplatten erhalten. Die Mecklenburgische, Pommersche und Preussische Seenplatte sind allgemein bekannt. Diese repräsentieren ja nur einen Teil des ganzen inneren Moränenlandgürtels rings um Fennoskandia.

Die Region der Moränentopographie ausserhalb Fennoskandia besteht aus mindestens zehn Seenplatten, die vorwiegend der Aussengrenze ihrer Region entlang 
liegen. Die Nummern der folgenden Gebiete entsprechen den Nummern der Karte $2 .^{\mathrm{I}}$

I. Das Boddenland des Limfjord ist ein äusserst flachwelliges Lehmmoränenland, das sich innerhalb des Randes der Südnorwegischen Eiszunge gebildet hat. Es kann aber nicht als eine Seenplatte gelten.

2. Die Silkeborgsche Seenplatte, hauptsächlich im Amt Aarhus, ist eine wohlausgebildete Seenplatte mit Lehmwellen von bis $172 \mathrm{~m}$ Meereshöhe (Ejer Bavnehöj).

3. Die Holsteinsche Seenplatte, hauptsächlich in der Landschaft Wagrien in Ost-Holstein, ist die nächste typische Seenplatte nit Erhebungen bis $164 \mathrm{~m}$ Meereshöhe (Bungsberg). Im schmaleren Schleswig giebt es auf den östlichen Halbinseln mächtige Lehmablagerungen, aber wenig Seen.

4. Die Mecklenburgische Seenplatte ist grösser und auch wohl ausgebildet. Höhen von 178 und $179 \mathrm{~m}$ werden erreicht (Ruhnerberg und Helpterberg).

5. Die Pommersche Seenplatte ist noch grösser und mächtiger mit Höhen von 234 und $33 \mathrm{I} \mathrm{m}$ (Steinberg und Turmberg).

6. Die Preussische Seenplatte ist von derselben Grössenklasse mit Höhen von 375 und $310 \mathrm{~m}$ (Höhe nördlich von Mlawa und Seesker Höhe). $\mathrm{Zu}$ diesem Gebiet gehören die Seenlandschaften westlich von Wilna.

7-8. Etwa $250 \mathrm{~km}$ nach innen von den anderen Seenplatten liegen noch einige, wie die kleine Seenplatte $z u$ beiden Seiten des Romeleåsen in Schonen, die Höhen von West-Litauen ( 7 ), die $227 \mathrm{~m}$ erreichen (südöstl. von Telschi), und die Höhen von dem nordwestlichen Livland (früher: Schwedisch-Livland) (8), die $3 \mathrm{I} 4$ und $324 \mathrm{~m}$ erreichen (Gaising-K. und Munna-Mäggi). Sie sind alle durch Seenreichtum gekennzeichnet.

9. Die Ost-litauische Seenplatte im Süden der Düna erreicht $270 \mathrm{~m}$ Meereshöhe (bei Swenzjany).

ı. Die Seenplatte von dem südöstlichen Livland (früher: Polnisch-Livland) im Norden der Düna erreicht $260 \mathrm{~m}$ (südöstl. von Rositten). Die Seenmenge ist wie bei der vorigen $\gg$ Platte» sehr gross.

I I. Die Seenplatte und die Höhen von Waldai erreichen $322 \mathrm{~m}$ Meereshöhe (Kamestik). Die nordwestliche Begrenzung der welligen Landschaft ist besonders scharf. Der Spiegel des Ilmensees liegt nur I $8 \mathrm{~m}$ über dem Meere.

Gewiss wäre es von Interesse, eine etwas nähere Kenntnis von den Mächtigkeiten und Massen der Lehmmoränenlandschaften zu erhalten. Diese Landschaften erinnern durch Seenreichtum und unregelmässige Hügelformen an Fennoskandia und können als eine Aussenzone dazu betrachtet werden. Die Verschiedenheiten sind jedoch in anderen Hinsichten gross.

Die geographische Bedeutung der äusseren Grenze der Moränengürtel wird beträchtlich dadurch erhöht, dass ausserhalb dieser Linie regelmässig ganz flache

T Die Seenplatten sind auf der Grundlage von Andrees Handatlas I 914 abgegrenzt worden. 
Sandebenen auftreten. Sie sind glaziofluviale Ablagerungsflächen in Verbindung mit den Flussebenen der Schmelzwasserströme, der sogenannten Urstromtäler.

Die Sandebenen sind nur teilweise angebaut, in Dänemark zum kleinen Teil mit Nadelwald bepflanzt, Plantagen genannt, sonst noch Heiden bildend und mit Heidekraut bewachsen. Im östlichen, kontinentalen Eichenlande nehmen weite Forste aus Nadelwald nebst Torfmooren die Stelle des Heidekrauts ein.

Die bekannteren Heiden sind die folgenden: Die Jütländische Heide (Karte 2, J. H.) nebst den Heiden des westlichen Schleswig und Holstein, die Lüneburger Heide (L. H.) sowie die des südwestlichen Mecklenburg, die Tucheler Heide (T. H.), die Johannisburger Heide (J. H.) und das Poljessjesche ehemalige Sumpf-, jetzige Waldgebiet.

4. Das Fennoskandische Landhebungsgebiet (Karte 2, innere, ausgezogene Linie) nach der Abschmelzung des Landeises wurde hinsichtlich seiner Realität und allseitigen Abgrenzung rings um Nordeuropa von Gerard De Geer festgestellt. ${ }^{\mathrm{I}}$ Diese Landhebung war bekanntlich am intensivsten längs der nordwestlichen Küste des Bottnischen Busens, wo sie $300 \mathrm{~m}$ betrug. Von diesem zentralen Teil von Fennoskandia aus sank der Betrag der Landhebung nach allen Richtungen hin bis zur peripheren Null-Isobase. ${ }^{2}$

Die Null-Linie ist zwar eine absolute Grenze der Landhebung, hat aber selbst keine Intensität, während die Intensität des Moränengebiets an seiner Grenze am höchsten ist.

Erst in einigem Abstand nach innen von der Null-Isobase beträgt die Landhebung so viele Meter, dass eine gehobene Küstenebene von geographischer Bedeutung entsteht (im Massstab 1: 16000000 beträgt dieser Abstand nur etwa $2 \mathrm{~mm}$ ).

Im Lehmmoränenland, wie im nördlichen Dänemark (Vendsyssel) und Kurland (Kurzeme), bildeten sich sandige Abrasionsebenen, die von Nadelwald oder Torfmooren eingenommen wurden.

Die gehobenen Küstenebenen des Urgebirgslandes sind durch Tonablagerungen in Senken und auf ebenen Flächen ausgezeichnet. Diese Ablagerungen bilden gute Ackerbaugebiete. Schon weit unter der marinen Grenze hören die Sedimente auf und werden durch ausgespülte, steinige Moräne oder nackte Felsen ersetzt.

Der Verlauf der Null-Isobase ist aus der Karte ersichtlich. Die Konformität des Landhebungsgebiets mit dem Moränengebiet ist augenfällig, aber das Landhebungsgebiet ist doch wesentlich kleiner, was natürlich erscheint.

Durch die regionalen Eigentümlichkeiten des Küstenlandes innerhalb des Landhebungsgebietes erhält dieses grosse geographische Bedeutung.

5. Das Kerngebiet der Nordischen Rasse (Karte 3, grobe Linien) ist nach einem

I Gcol. För. Förh., Stockholm 1888.

2 Nach G. De Geer, Kontinentale Niveauveränderungen im Norden Europas, C. R. du XI;e Congrès Géologique International, Stockholm r9ro. 


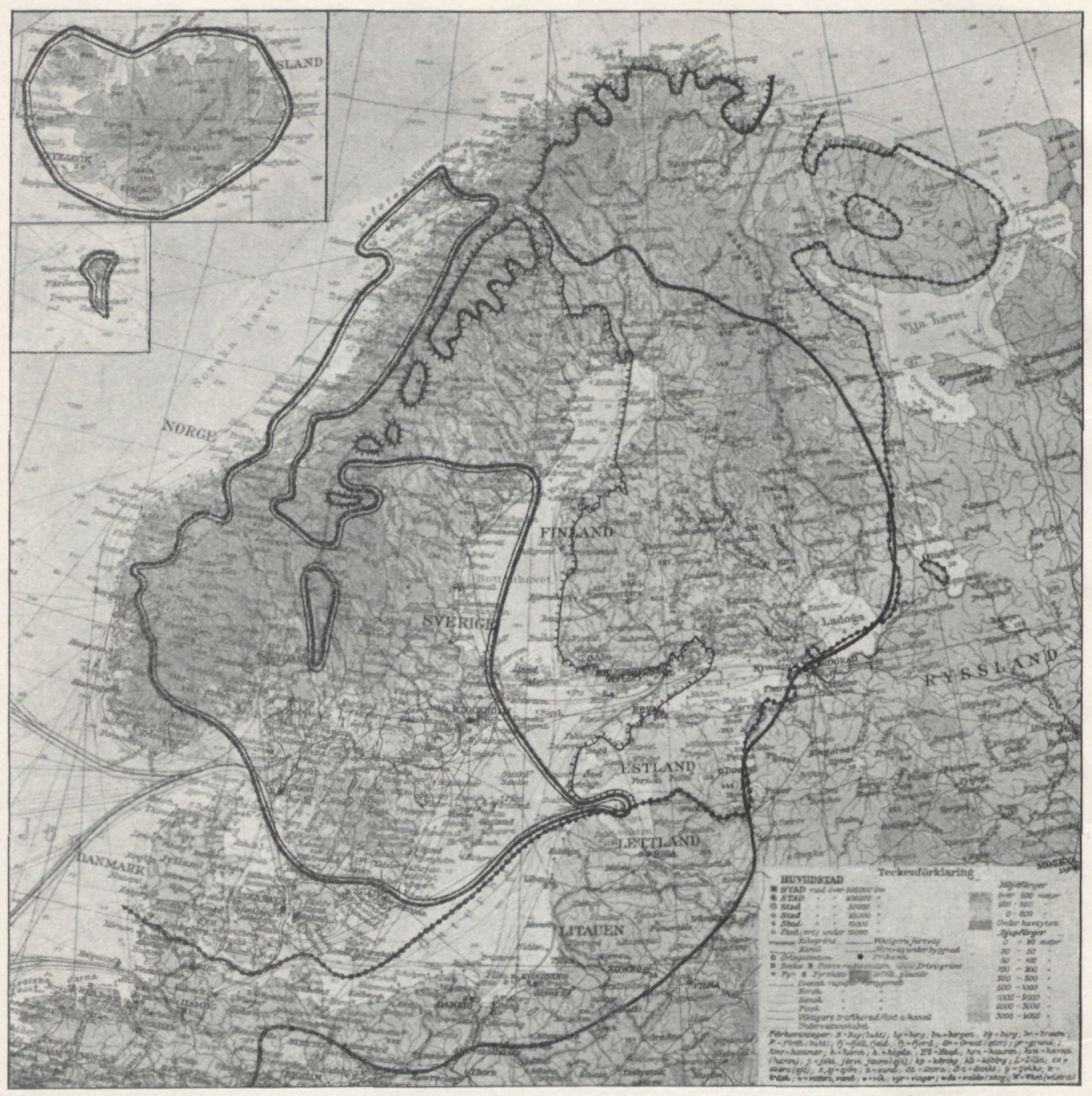

Karte 3. Das Kerngebiet der Nordischen Rasse (ausgezogene, grobe Linie, weil grobe Linie mit feiner Nebenlinie höchster Intensität bezeichnet). Die beiden fennoskandischen Sprachgebiete (feinere gepunktete Aussergrenze nebst feinere gezahnte Teilungsgrenze der beiden Gebiete). Massstab I : 16000000.

vom Verf. ausgeführten Versuche kartographischer Zusammenstellung anthropologischer Untersuchungen dargestellt. ${ }^{I}$ Das Material war ausserhalb Schwedens schwer vergleichbar und teilweise mangelhaft, immerhin nunmehr aber besser, als es früher zur Verfügung stand.

I In H. Lundborg und F. J. Linders, The Racial Characters of the Swedish Nation, The Swedish State Institute for Race Biology, Uppsala 1926, S. 162. Vgl. Verf. in Ymer 1927, S. 308. 
Bei der Abtrennung des nordischen Völkergebietes wurden berücksichtigt die massenhaft beobachteten anthropologischen Merkmale der Körperlänge, der Augenfarbe und der Kopfform. Drei besonders geeignete Isarithmen der Körperlänge, zwei der Augenfarbe und drei der Kopfform wurden ausgewählt und kombiniert. Auf Grund einer deutlichen Konformität der Grenze skandinavischer Sprachen und der anthropologischen Grenzen wurde auch die erstere als ein neunter Faktor beigefügt.

Für die Karte 3 wurden nur die Linien ersten Intensitätsgrades (ausgezogene, grobe Linie) und siebenten Intensitätsgrades (grobe Linie mit feiner Nebenlinie) ausgewählt.

Die innere Linie höherer Intensität umfasst das eigentliche Kerngebiet der Nordischen Rasse oder des Nordischen Völkergemisches. Dieses Gebiet ist geographisch charakteristisch, weil es gerade den zentralen, breiteren Teil der eigentlichen Skandinavischen Halbinsel nebst dem entlegenen Island einnimmt. Die nördlichen, westlichen und südlichsten Teile der Halbinsel scheiden aus.

Die äussere Linie niederer Intensität umfasst etwa das Gebiet nordischer Bevölkerung. Die Grenze ist keine absolute. Man könnte gewiss andere Intensitätslinien nicht nur innerhalb, sondern auch ausserhalb dieser Linie konstruieren. Sie zeigt die wahrscheinliche Verwandtschaft der skandinavischen Völker mit den Völkern rings um die Ostsee und die Nordsee.

Die nordischen Halbinseln mit direktem Anschluss an den Kontinent haben Bevölkerungen von etwa demselben Intensitätsgrad. Die Finnen und Esten sind keine Mongolen mehr, aber die Lappen sind es. Ihr Gebiet scheidet aus.

Die Konformität der Rassenlinien mit den naturgeographischen Linien ist von Bedeutung für die Auffassung von Nordeuropa als einer geographischen Region.

6. Die beiden fennoskandischen Sprachgebiete (Karte 3, feinere, gepunktete und gezahnte Linien). Die skandinavischen Sprachen: das Schwedische, das Norwegische, das Isländische und das Dänische, bilden ja sprachlich eine Gruppe, deren Grenzen konform mit den Grenzen des inneren Kerngebietes der nordischen Rasse verläuft.

Die Südgrenze der skandinavischen Sprachen umfasst Dänemark und liegt in der Ostsee (gepunktete Linie). Die Ostgrenze bildet vier Ausläufer, je einen für den Rigabusen, den Finnischen Busen, den Bottnischen Busen und für die Eismeerküste. Sie ist ebenfalls konform mit den Rassenlinien. Sie bestätigt, dass die skandinavischen Völker als seefahrende von den Küsten aus siedelten, im Gegensatz zu den ostbaltischen Völkern.

Von dem schwedischen Sprachgebiet rings um den Rigabusen im neunten Jahrhundert ${ }^{\mathrm{I}}$ ist noch Runö erhalten geblieben. $\mathrm{Zu}$ beiden Seiten des Finnischen Busens wird noch schwedisch gesprochen, sowie zu beiden Seiten des Bottnischen

I Rolf Nordenstreng, Vikingafärderna, Stockholm 1926, S. 145.

9. Geografiska Annaler 1928. 
Busens, wenn auch nicht überall und speziell nicht an den entlegensten Enden der genannten Busen. Das Norwegische wird der Eismeerküste entlang bis zur hinteren Seite des Varangerfjords gesprochen, während das Lappische und Finnische in dem fast menschenleeren Inneren des nördlichen Fennoskandia vorherrschen.

Die Hauptmasse des östlichen an den Kontinent anschliessenden Halbinsellandes von Nordeuropa gehört zu dem Gebiet der verwandten Sprachen des Finnischen, Lappischen und Estnischen. Lettland und Litauen bilden ein eigenes Sprachgebiet von zwei unter sich verwandten Sprachen.

Die schwedisch-finnische Sprachgrenze teilt Fennoskandia in zwei Teile, während die Ostgrenze der finnischen Sprachgruppe recht genau mit den oben besprochenen Naturgrenzen übereinstimmt. $\mathrm{Da}$ auch die übrigen Kulturgrenzen die östliche Lage haben, so wäre es nutzlos, die schwedisch-finnische Sprachgrenze als Regionsgrenze zu prüfen. Die finnische Ostgrenze dagegen könnte dazu beitragen, die natürlichste Lage dieser Grenze zu bestimmen.

Es scheint somit richtig, die Nordeuropäische Region als sprachlich in zwei grosse Sprachgebiete geteilt aufufassen.

Das Lettisch-Litauische Sprachgebiet könnte vielleicht auch zu Nordeuropa gerechnet werden. Da dies aber etwas fraglich erscheint und jedenfalls nicht notwendig ist, wurde es nicht getan.

Das kleine Sprachgebiet der Syrjänen in Dorfe Lowosersk in der Mitte der Kolahalbinsel wurde auch weggelassen, das Finnisch-Vepsische an dem Onegasee dagegen mitgerechnet.

7. Das Verbreitungsgebiet des protestantischen Christentums (Karte 4, gepunktete Linie) war in älteren Zeiten wichtiger als die Verbreitung der Sprachen. Es war einfach das Gebiet abendländischer Zivilisàtion, genau wie vor der Reformation das ganze Verbreitungsgebiet des abendländischen Christentums.

Die Ausbreitungsverhältnisse der Konfessionsgebiete und der Staaten stehen in wesentlichen Wechselbeziehungen zu einander im alten europäischen Norden.

Der Polnisch-Litauische Staat, der Deutsche Ordensstaat und der Schwedische Staat waren hier die Träger abendländischer Konfession und Zivilisation. Der erstere verblieb bei dem römischen Katholizismus, während die anderen Staaten 1525-1527 sich der Reformation anschlossen. Seit 1561 und I62 I gehörten zu Schweden Estland und Livland und damit die ganze Ostgrenze des protestantischen Christentums gegen das griechisch-katholische.

Die Übereinstimmung von Staats- und Konfessionsgrenze wurde im Mittelalter durch Zwangsbekehrungen, in der neueren Zeit durch mehr oder weniger freiwilligen Völkeraustausch sowie durch kulturelle und andere Einfüsse befördert.

Der Protestantismus hat nordöstlich des Ladogasees die schwedisch-russische Reichsgrenze von 1617 , jetzt die finnisch-sovjetische Grenze, noch nicht erreicht. 


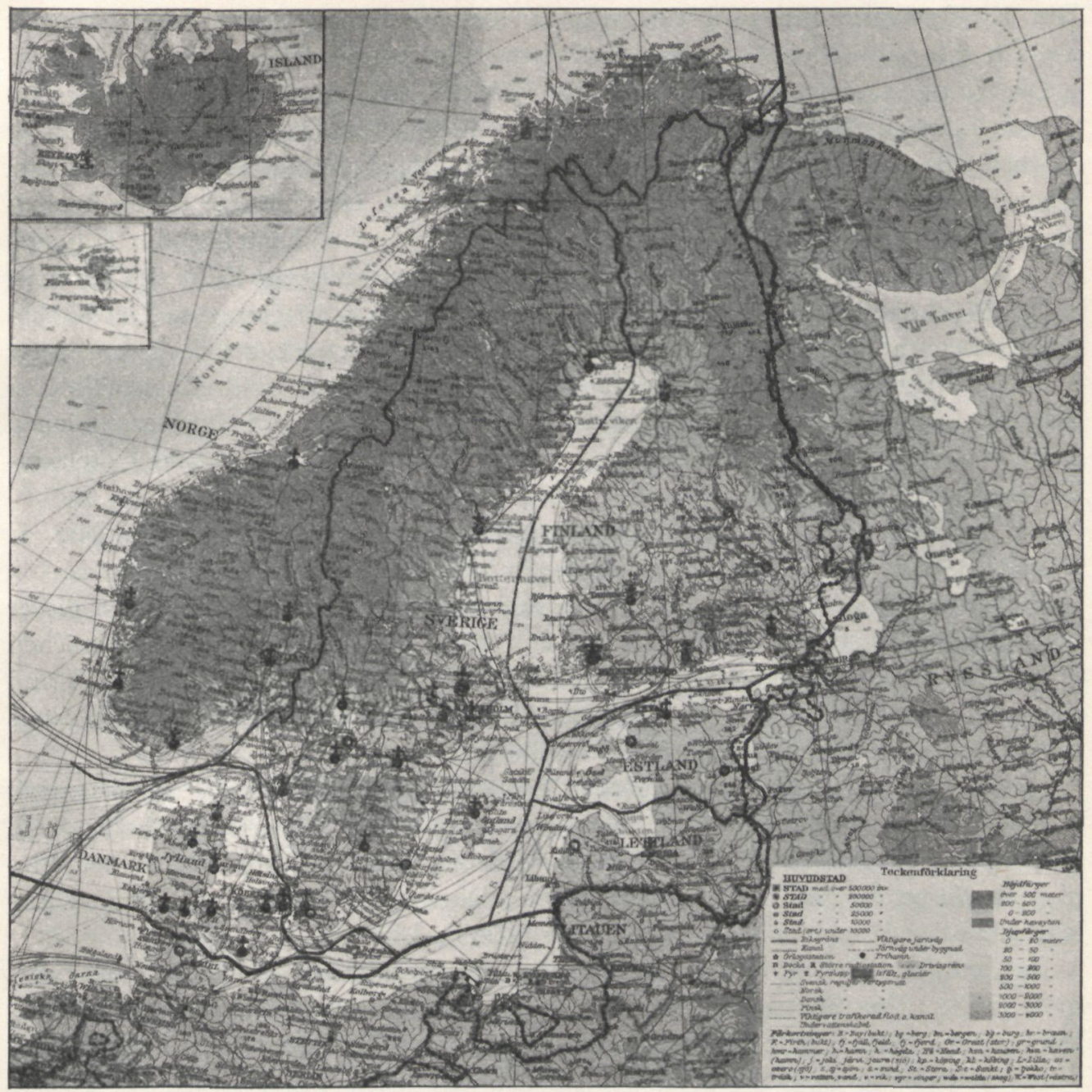

Karte 4. Das Verbreitungsgebiet des protestantischen Christentums (gepunktete Linie) mit jetzigen und frïheren Bischofssitzen. Die heutigen Staatsgebiete (ausgezogene Linien).

Massstab I : 16000 000.

Im Gegenteil, die griechisch-katholische Konfession hat während zweihundertjähriger russischer Herrschaft über die Ostseeprovinzen, mit Ausnahme des heutigen Leningrad, keine nennenswerten räumlichen Fortschritte gemacht.

Die Lage der Konfessionsgrenze etwas innerhalb der heutigen Reichsgrenzen von Estland und Lettland ist im Gegenteil eine Folge der östlichen Verlegung dieser Staatsgrenzen im Verhältnis zu der früheren schwedischen Reichsgrenze. 
Die Konfessionsgrenze in Preussen gegen den römischen Katholizismus spiegelt vielfach die politischen Grenzen der Reformationszeit wieder.

Die Karte 4 veranschaulicht auch die Gebiete der sieben nordischen protestantischen Staatskirchen, die mit den Staatsgebieten zusammenfallen, sowie deren 35 Bischofssitze (gefüllte Ringe mit Kreuze) darunter den schwedischen Erzbischofssitz Uppsala und den nach der Trennung von Schweden I809 eingerichteten finnländischen Erzbischofssitz Åbo. Ehemalige Bischofssitze sind auch angedeutet (ungefüllte Ringe). Die Bischofssitze sind Hauptorte der protestantischen Stifte des Nordens.

8. Die heutigen nordischen Staatsgebiete (Karte 4, ausgezogene Linien) sind die der zwei tausendjährigen Staaten Schweden und Dänemark, die der zwei realiter hundertjährigen Staaten Norwegen und Finnland, sowie die der drei neugebildeten Staaten Island, Estland und Lettland. Als Tochterstaaten Schwedens können gewissermassen die östlichen Staaten, Finnland, Estland und Lettland gelten, als Tochterstaaten Dänemarks ebenso Norwegen und Island.

Die nordische Region besteht geopolitisch aus drei nord-südlichen Teilen: I. Dänemark-Norwegen-Island, 2. Schweden, und 3. Lettland-Estland-Finnland.

Während der historischen Zeit haben mehrere staatliche Kombinationen dieser fünf Teilgebiete stattgefunden. Gewöhnlich waren die drei Gebiete des westlichen Drittels in einem dänischen Reiche vereinigt rings um die Beltsee, Kattegatt und Skagerrak, während zwei bis alle vier Gebiete der zwei östlichen Drittel rings um die Ostsee ein schwedisches Reich bildeten.

Das westliche Drittel der nordischen Staatengruppe wird durch das Skagerrak in einen kleineren südlichen Teil, Dänemark, und einen grösseren nördlichen Teil, Norwegen, zerlegt. In ähnlicher Weise wird das östliche Drittel durch den Finnischen Busen in zwei Teile zerlegt, einen kleineren südlichen, Lettland und Estland umfassend, und einen grösseren nördlichen, Finnland.

Das mittlere Drittel ist das einzige, das im wesentlichen durch die ganze Region reicht. Das Staatsgebiet des heutigen Schwedens wird nicht durch die Mittelschwedische Senke mit ihren grossen Seen in zwei Teile zerlegt. Diese Senke bildet vielmehr ein wichtiges zusammenhaltendes Siedlungsgebiet mit der Hauptund Halbmillionenstadt Stockholm am östlichen Ende und der Hafen- und Viertelmillionenstadt Göteborg am anderen Ende. Schweden nimmt nicht nur den zentralsten Teil der nordischen Staatengruppe ein, es wird auch durch die höhere Lage des mittleren, schwedischen Teiles der nordischen Quersenke SkagerrakFinnischer Busen zum bedeutendsten Staate der Gruppe.

Das scheidende Meer ist die Ursache der heutigen Selbständigkeit Islands wie der Norwegens. Es war ein mitwirkender Faktor bei der Entwicklung finnländischer Selbständigkeit. Es wird auch dazu beitragen, Estland als selbständigen Staat Finnland gegenüber zu bewahren, trotz der Ähnlichkeit der Sprachen.

Die Aussengrenze der nordischen Staategruppe ähnelt der Grenze der fenno- 
skandischen Spıachen (Karte 3) Die wesentlichen Unterschiede bestehen darın, dass die protestantische Republik Lettland auf fruher schwedischem Territorium auf der Staatenkarte hinzugefugt wurde, wahrend Ost Karelen und die Kolahalbinsel weggelassen wurden Doch bildet Ost-Karelen schon im Bunde der SovjetUnion eine Karelische Autonome Sozlalistische Sovjet-Republik (ASSR), deren Ostgrenze so ziemlich mit der Ostgrenze von Fennoskandia und der finnischen Sprache, zusammenfallt Die Karelısche Republik als nicht suveraner Sovjet-Staat kann jedoch nicht der nordischen Staatengruppe zugerechnet werden

Alle die nordischen Hauptstadte liegen an der Kuste Keıne liegt in der nordlichen Halfte der Region Vier liegen um den zentralen Teil der Ostsee herum, zwel an den Einfahrtseen zur Ostsee, eine auf Island

9 Die Maximalverbreitung der zwei tausendjährigen nordischen Staaten wahrend der neueren $Z$ eit ist hier durch eine gemeinsame Linie veranschaulicht worden (Karte 5, aussere, grobe Lime) Es sind die ehemaligen Territorien von Schweden und Danemark, die zusammen etwa dasselbe Gebiet umfassen wie die jetzige Gruppe der sieben nordischen Staaten

Die zwe1 alten Hauptstaaten des Nordens umfassten sogar mehr Oldenburg (Danemark), Bremen Verden (Schweden), Holstein (Danemark), Mecklenburg (Danemark im Mittelalter: 1214-1227), Vorpommern (Schweden), vier preussische Seestadte (Schweden) und Ingermanland (Schweden)

Die Karte 5 zeigi hauptsachlich Gebiete, die wahrend 1660-1720, oder eines Telles dieser Zeit, zu Schweden oder zu Danemark gehort haben Von alteren Besitzungen 1st nur Mecklenburg durch eine gestrichelte Linie bezeichnet, von Besitzungen de facto nur Kurland, das mehrfach unter schwedischer Verwaltung stand. Als neuzeitlıche Besitzung w urde Kurland bei der Synthese berucksichtigt.

Obwohl fur diese Untersuchung ohne Belang, gibt Karte 5 auch eine Ubersicht uber die Dauer schwedischer und danischer Herrschaft uber die verschiedenen Flachen des gemeinsamen Verbrettungsgebıetes der beiden Staaten

Land, das mehr als tausend Jahre hindurch zu dem Staate Schweden gehort hat, ist grob horizontal gestrichelt; solches. das mehr als tausend Jahre zu Danemark gehorte, ist grob vertıkal gestrichelt. Diese zweı Gebiete sind die Kernlander der betden Staaten

Zwischen die Kerngebiete schaltet sich eine Ubergangszone ein, die abwechselnd zu Schweden und zu Danemark gehort hat, und die jetzt seit 1645 oder I658 schwedisch 1st.. Dieses Gebiet ist grob schrag bezeichnet, da es mehr als tausend Jahre lang entweder zu Schweden oder zu Danemark gehort hat

In ahnlıcher Weise ist 500 jahrige Zugehorigkeıt mittelst feiner Strıchelung bezeichnet, horizontal wenn schwedisch, vertikal wenn danisch, und schrag wenn die Perıode auf die beiden Machte vertelt war. Eine Zugehorigkeit von 450-500 Jahren wird durch Strichelung entlang der Grense bezeıchnet 


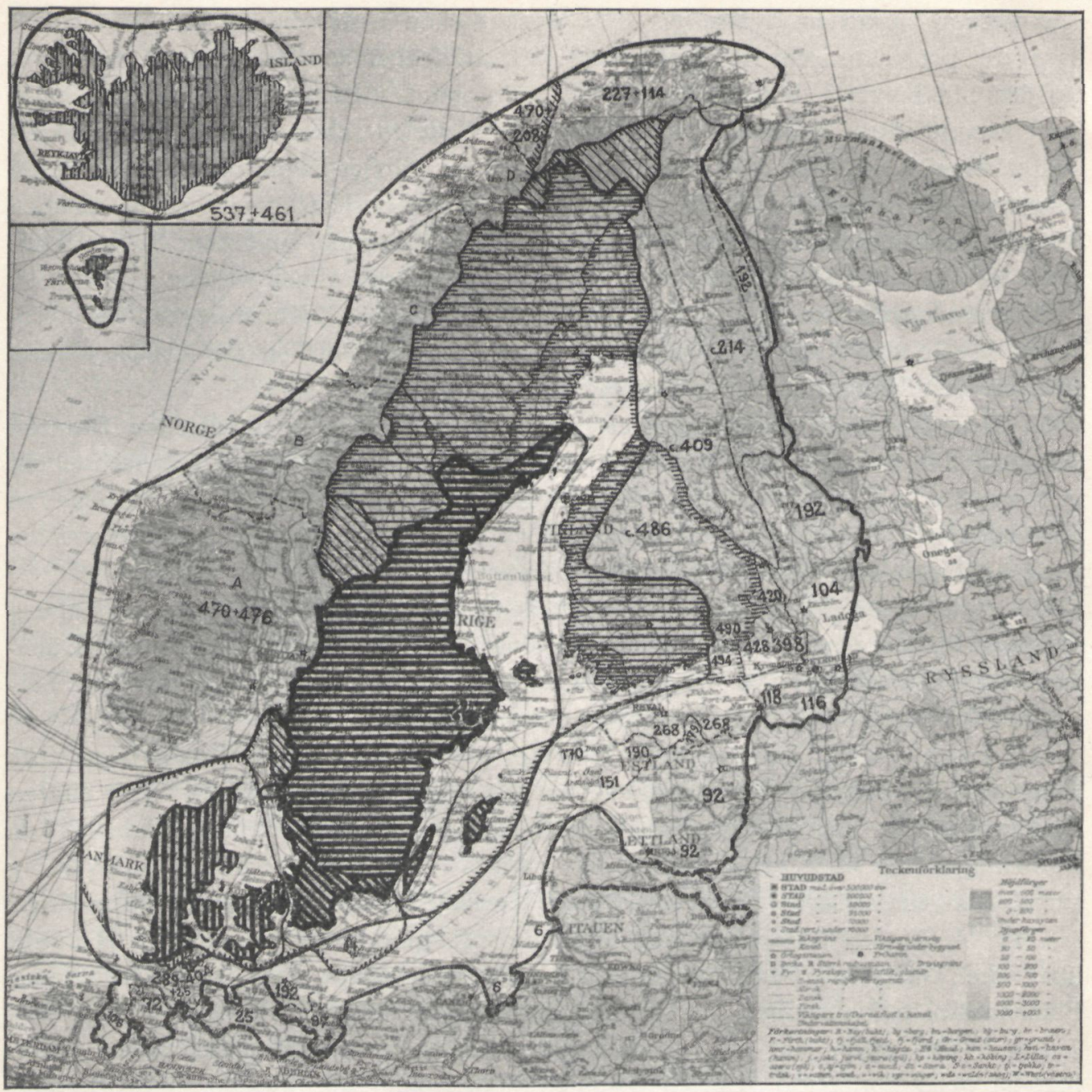

Karte 5. Die Maximalverbreitung des zwei tausendjährigen nordischen Staaten während der neueren Zeit (äussere grobe Linie). I ooo-jährige Zugehörigkeit (grobe Strichelung) und 50o-jährige (feine Strichelung). Massstab i : 16000000.

Die übrigen Gebiete werden nur durch Ziffern markiert. . Ihre Grenzen lassen sich leicht in Linien gleicher Zugehörigkeitsdauer umwandeln. Man könnte eine Linie für je hundert Jahre Zugehörigkeit konstruieren.

Estland mit Inseln, Vorpommern und Norwegen ${ }^{\mathrm{T}}$ haben die summierten Ziffern schwedischer und dänischer Zugehörigkeit erhalten, wozu für Norwegen und Island

I Die Gebiete A, B, C, D haben etwas verschiedene historische Relationen zu Schweden gehabt. 
nach einem Pluszeichen hinzu gefugt ist die Anzahl von Jahren als selbstandiger Staat und als Nebenland Norwegens. Die Zeiten sind bis 1928 berechnet.

Wenn man die norwegischen und isländischen Staatenbildungen berucksichtigt, so könnte man wohl auch der nordisch organisierten ostbaltischen Staaten gedenken und ihre verschiedenen Selbstandigkeitsalter nach einem Pluszeichen beifugen, was hier nicht geschehen ist. Nur schwedisch-danische Herrschaft ist ausserhalb des eigentlichen Skandinavien berucksichtigt worden.

Die Flachenbezeichnungen der Karte 5 lassen drei wichtige Zonen hervortreten, namlich (I.) die uber tausendjahrige Zone der Kerngebiete, (2.) die 500-I 000jährige Zone mit Kiel und Bohuslan und mit den weiten nordostlichen Landern, das nördliche Schweden und das westliche Finnland; endlich (3.) die 0-500jahrige Zone, welche die ubrigen schwedisch-danischen Gebiete als breiter Aussenrand auf alle Seiten umgibt.

Eine kartographische Synthese des geographischen Nordeuropa ist versucht worden. Die neun Faktoren, die behandelt wurden, haben mit einer Ausnahme absolute Grenzen und eignen sich verhaltnismassig gut zu einer kartographischen Synthese hinsichtlich ihrer Peripherien und Flachen. $\mathrm{Da}$ in diesem Falle die regionale Werte der einzelnen Faktoren nur schwer vergleichbar sind, so sind versuchsweise alle gleichgestellt worden. Als Intensitat der Region wird fur jede Flàche nur die Zahl der Faktoren angegeben. Karte 6 ist ein Bild der durchgefuhrten Aufeinanderlegung der neun Flächen mit den daber durch Eröffnung von allen Linienkreutzen erhaltenen neun synthetischen Linien. ${ }^{\mathrm{I}}$

Die fünfte synthetische Linie ist die mittelste und auch realiter unter den neun Linien die geeignetste Grenalinie für das geographische Nordeuropa. Das Gebiet zenirde besser das skandinavisch-baltische Gebiet genannt werden, oder einfach Baltoskandia.

Die vierte Linie umfasst schon Stucke von Norddeutschland und von dem russisch sprechenden Ost-Karelen. Die sechste ist die nachstbeste. Die siebente ist weniger gut, da sie ganz allein laufend Estland Lettland und Jutland halbiert.

Die Gesellschaftlichkeit der synthetischen Linien ist von Bedeutung. Die Bindel von mehreven synthetischen Linien zeigen noch besser, als es eine einzige Lanie tun kann, die wahren Grenzen der Region.

In dem Falle von Baltoskandia und den gewahlten neun Faktoren erscheinen mehrere Linienbundel; so ein Bundel von neun Linien ausserhalb der nordlichsten norwegischen Kuste, eines von funf Linien ostlich der Kolahalbinsel und ein anderes von drei Linien westlich davon. Sieben Linien bilden ein ziemlich geschlossenes Bundel in Aunus, uber den Ladogasee und die Karelische Landenge. Funf von thnen gehen weiter durch Ingermanland und den Peipussee fort, drei begren-

r Das methodische ist in schwedischer Sprache behandelt worden in Ymer 1927, S 308. 


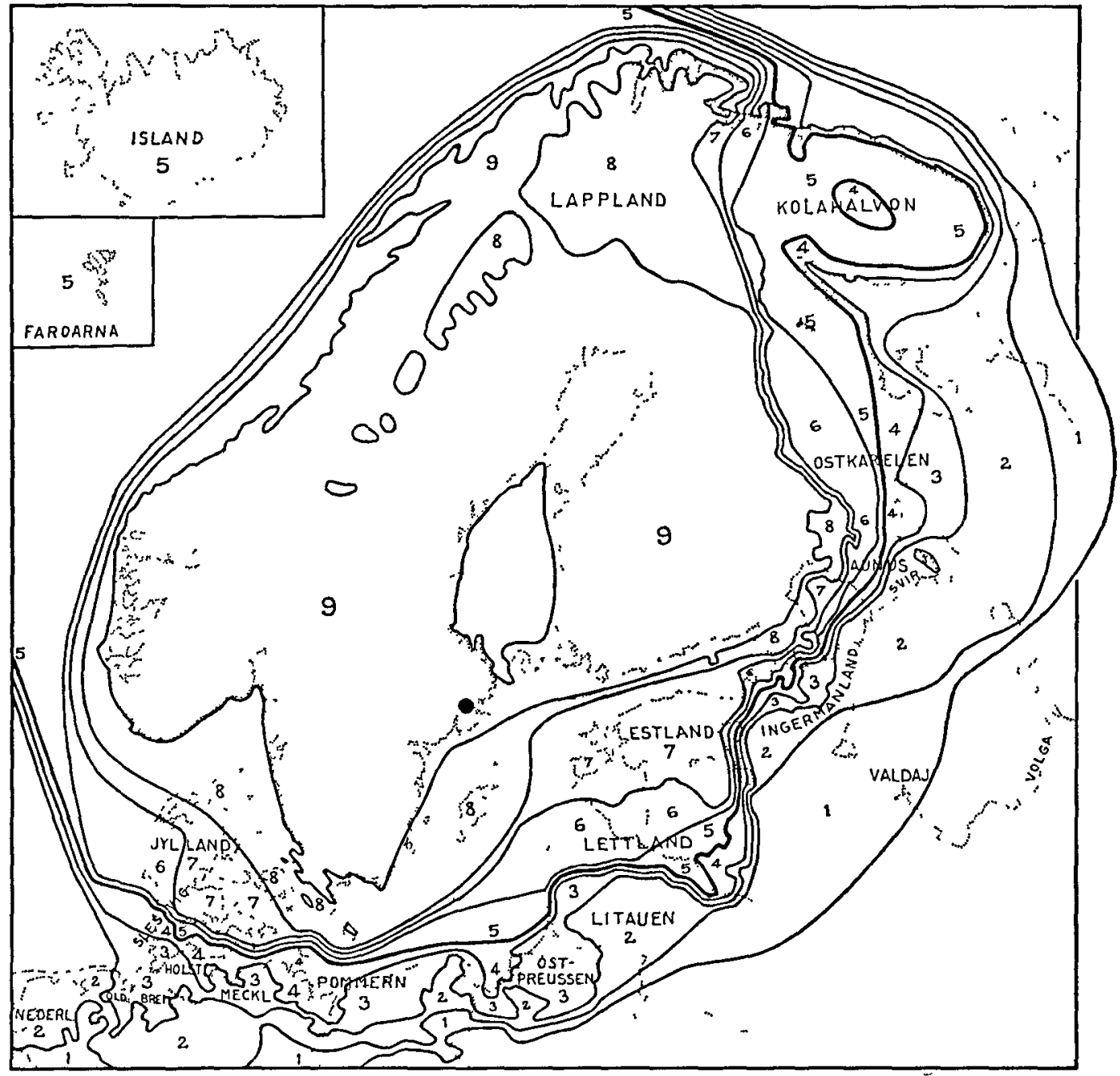

Karte 6. Eine kartographische Synthese der geographischen Region Baltoskandaa ist hier versucht worden. Die Ziffern geben die Anzahl der auf jeder Flache zusammen auftretenden Faktoren an. Massstab $1: 16000000$.

zen Lettland im Suden, vier scheiden Schweden und Deutschland, drei Dảnemark und Deutschland. Island ist von wenigstens funf dieser Linien umschlossen.

Danemark, Estland und Lettland sowie Island mussen zu Baltoskandia gefuhrt werden. Bezüglich Estland und Lettland wird die Schlussfolgerung von Michael Haltenberger somit bestatigt. ${ }^{1}$

Die Lage und Form der Regionsgrenze kann in Einzelheiten diskutiert werden,

I Michael Haltenberger, Gehort das Baltikum zu Ost-, Nord- oder zu Mitteleuropa? Publicationes Instituti Universitatis Dorpatensis Geographici I, Dorpat 1925. 
kann durch Wahl anderer Faktoren vielleicht verbessert werden, so durch bessere Bestimmung der Grenzlinien der gewahlten Faktoren. Einige Faktoren konnen als wichtigere etwa doppelt gerechnet werden. Es ist jedoch, wie aus der hier vorgelegten Synthese hervorgeht, wahrscheinlich, dass die geographische Region Baltoskandia, weiter gefasst werden muss als das geologische Fennoskandia.

Die allgemeine Form und Lage der Region Baltoskandia kann nach der Bestzmmung ihrer Grenze aveiter bestatigt werden, einmal durch eine Untersuchung ihres Kerngebiets, dann auch durch ein Studium ihrer Aussensphare, wobei eine gezvisse Konformitat der drei Zonen erwartet werden muss.

Kerngebiet und Aussensphäre von der Region Baltoskandia. Die neun Faktoren, die hier benutzt worden sind, haben meistens zu wenig ausgepragte oder doch zu wenig durchforschte Intensitatsverhaltnisse, um eine Kartierung der Kerngebiete zuzulassen. Verf. hat Studien in dieser Beziehung in Angriff genommen, bezuglich der Intensitat der nordischen Rasse und der Dauer der Staatsgebiete.

Die verschiedenen Intensitatsgrade mussten auch verschiedene Grade der Individualităt der zu bestimmenden Region ausdrucken. Das Kerngebiet musste die charakteristischen Eigenschaften der Region in verstarktem Masse besitzen.

Die Lage des Baltoskandischen Kerngebietes in den breiteren, sudlichen Teil der Skandinavischen Halbinsel, oder hauptsachlich dort, ist jetzt wahrscheinlich (Karte 3). Das Kerngebiet liegt somit nicht ganz in Zentrum der regionalen Flache, sondern etzuas exzentrisch nach Sudwesten verruckt (Karte 3 und 5).

Die andere erganzende Untersuchung etwaiger Phanomene einer Baltoskandischer Aussensphare ist auch nicht besonders weit vorgeschritten. Die Karte 7 bringt einige Beitrage zur Beleuchtung dieser Frage.

Der ausserste Rand des nordischen Landeises ist eingetragen (feine Linie) nach Gerard De Geer ${ }^{1}$. Sie geht durch London, dem Unterrhein entlang, langs Thuringerwald, Erzgebirge, Karpathen, dann ostwarts uber die Schwarzerdezone Russlands.

Der Bereich dieser weitesten Verbreitung des Landeises ist durch lehm- und sandreiche Moranenebenen gekennzeichnet, die ebenso gut angebaut sind wie die jungeren Moranenlandschaften. Sie haben indessen die landschaftlichen Sonderzuge einer Lehmmoranenlandschaft eingebusst.

Die Verbreitung des Landeises ist sicher eine Folge mehrerer Faktoren, unter denen der Abstand von der Eisscheide der skandinavischen Plateauregion, wenigstens innerhalb Flachland-Europas, auch wichtig erscheint.

Von anderen, kartographisch schon festgelegten nordeuropaischen Verbreitungserscheinungen mag die totale Flache der protestantischen Konfessionen erwahnt werden.

Kommenden Untersuchungen ist es vorbehalten, eine geeignete aussere Grenze der nordischen Rasseneinmischung festzustellen.

I Gerard De Geer, Om Skandınaviens geografisha utveckling efter istıden, Stochholm I 896 , Tafel I, Den stora nedisningen 


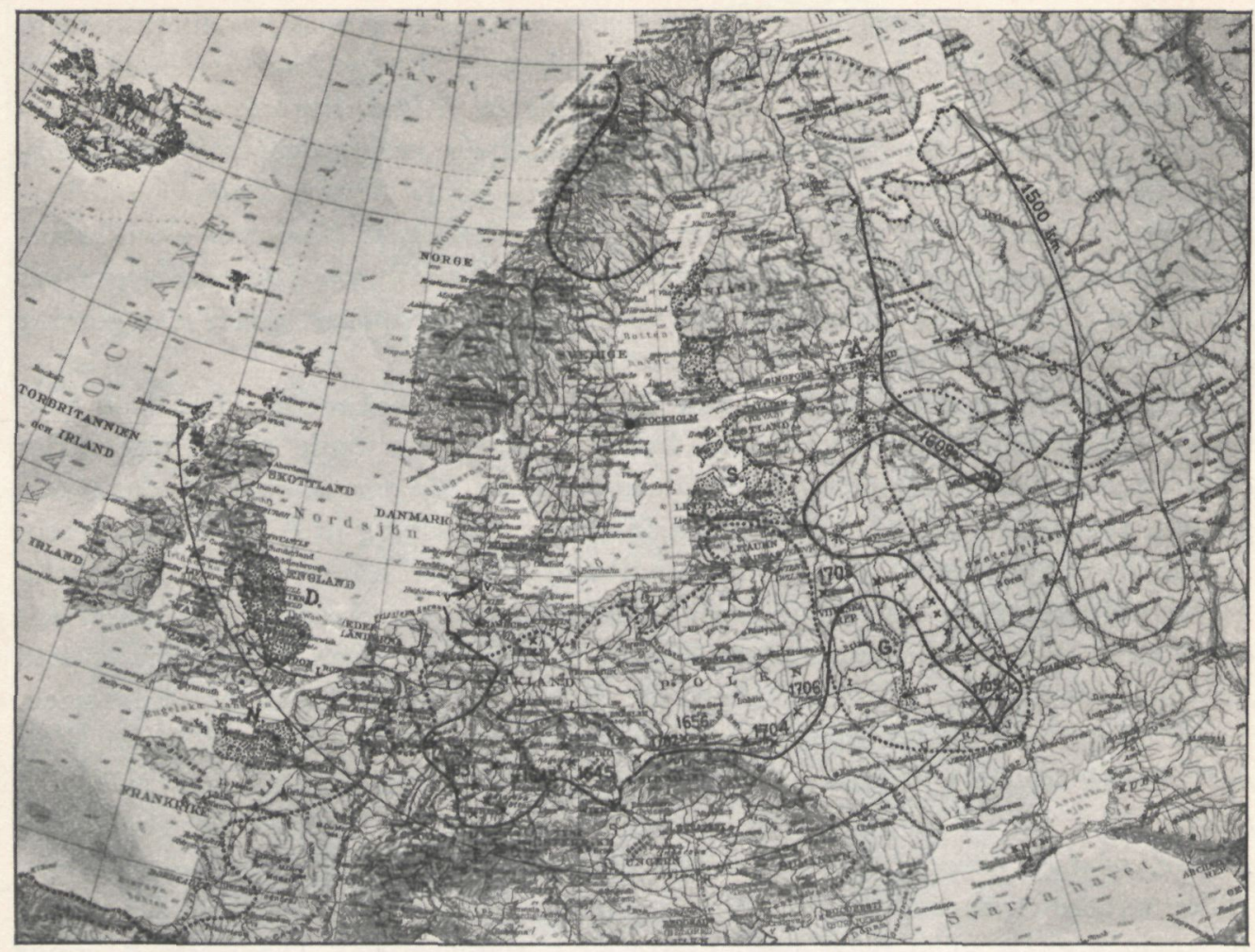

Karte 7. Phänomene einer nordischen Aussensphäre: der äusserste Rand des nordischen Landeises (feine Linie, I-I); Wikingerzüge 850-1050 (punktierte Linie); Wikingerstaaten (punktierte Flächen); Muttersland der Wikinger (gepunktete Linie V-V); Zone des Okkupationsgebiete schwedischer Armeen r609-1709 (grobe Linie); Kreislinie I $500 \mathrm{~km}$ von Stockholm.

Massstab $\quad$ : 32000000 .

Historische Aussengebiete lassen sich zur Zeit etwas besser definieren. So sind die Wikingerzüge während der zweihundertjährigen Periode $850-1050 \mathrm{n}$. Chr. jetzt auf der Karte 7 nach den neuen Schilderungen von Rolf Nordenstreng ${ }^{\mathrm{I}}$ sowie nach Kartenstudien eingetragen worden (punktierte Linie).

Besonders wurden markiert (punktierte Flächen) die folgenden Wikingerstaaten, die durch die Ansiedelung Skandinavischer Nordmannen in grösseren Mengen entstanden: Normandie (N.) mit Rouen als Hauptstadt, Ostangeln mit Norwich und Northumberland mit York, beide zusammen oft Danelagen (D.) genannt, weiter die Reiche Dublin und Island (I.), nebst kleineren Inseln und Inselgruppen von Man bis zu den Färöarna. Diese Kolonisationsstaaten liegen jenseits der Nordsee von dem Mutterlande der Wikinger aus (Karte 7 , gepunktete Linien, V-V, im Norden und Süden des Mutterlandes).

\footnotetext{
I Rolf Nordenstreng, Vikingafärderna, Stockholm 1926.
} 
Östlich der Ostsee liegen weitere Kolonisationsgebiete langs der finnlandischen Gegenkusten und rings um den Rigaer Busen, wo nach Nordenstreng Kurland als eine schwedische Syssla organisiert wurde mit Saborg als Hauptstadt (S.), einem Vorlaufer Rigas.

Es ist wahrscheinlich, dass die schwedische Kolonisation dieser Zeit das nordische Rassenelement in Teilen der ostbaltischen Lander um die Prozente verstarkt hat, die in der vollstandigeren Rassenkarte (vergl. S. Io, die Note) dort zum Vorschein kommen.

Noch ostlicher am Ende des Wassersystems Finnischer Busen-Newa-Ladogasee und an der Mundung der Volchowa lag Aldeigjuborg (A) als Hauptstadt eines Wikingstaates Ein zweiter Staat folgte im Suden rings um den Ilmensee. Dessen Hauptstadt war Holmgård, das heutige Nowgorod, und die nàchstgrósste Stadt war Staraja Russa, was ja noch heute Alte Schwedenstadt bedeutet.

Im Inneren Russlands folgten die Wikinger dem Dnjepr und bildeten das Gårdarike (G.) mit Kijev als Hauptstadt, aber sie folgten auch der oberen Wolga, kleinere Reiche grundend.

Die zusammenhangende Region des Einflusses der Wikinger 850-1050 erstreckt sich von Archangelsk im Nordosten bis Pamplona im Sudwesten. Sie ist breiter rings um die Seewege in Westeuropa und langs den Flusswegen in Osteuropa. Obwohl naher liegend, gehorten die grossten Teile von Deutschland und Polen nicht zu dem Gebiete der Wikingerzuge.

Dass diese Gebiete jedoch zur ausseren Wirksamkeitssphäre Baltoskandias gehören, erhellt aus dem Studium der Zone der Okkupatzonsgebiete schwedischer Armeen wahrend der hundertjahrigen schwedischen Grossmachtperiode, hier die fahre von I609 bis I709 umfassend. Der Aufstieg zur Grossmachtstellung wie der Verlust derselben trafen beide, wie naturlich ist, etwas spater ein, um I63I und I72I.

Die Grenze der Okkupationsregion (Karte 7, grobe Linie) wurde sukzessiv von Westen nach Osten aktualisiert (Karte 7, die Jahreszahlen).

Due Zonen der Wikingerziige und der Okkupation der Schwedischen Grossmacht bulden zusammen eine Aussensphare von Baltoskandia, die ihrer Natur nach eine Abstandzone ist.

Um diese Auffassung zu prufen, wurde eine $1000 \mathrm{~km}$ breite Zone ausserhalb der Regionsgrenze Baltoskandias konstruiert. Ein etwas besseres Resultat wurde erreicht durch eine Kreisline von $1500 \mathrm{~km}$ Radius mit Stockholm, der zentralsten Hauptstadt der Region als Mittelpunkt (Karte 7).

Man darf von wenigen Faktoren einer weiten Aussenzone ohne eigenen regionalen Charakter keine bessere Übereinstimmung erwarten. Ihr blosses Dasein ist jedoch von Interesse. 


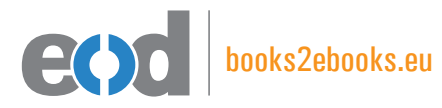

\section{www.books2ebooks.eu}

e-raamat EOD kaudu

Q $(20)$ eBooks on Demand
俞 TARTU ÜLIKOOL RAAMATUKOGU 